\title{
ANALISIS PENERAPAN SISTEM INFORMASI MANAJEMEN RUMAH SAKIT DALAM UPAYA PENINGKATAN PELAYANAN KESEHATAN DI RSUD ANDI MAKKASAU PAREPARE
}

\section{Analysis the Application of Hospital Management Information Systems in an Effort to Improve Health Services in Andi Makkasau Parepare}

Sadriani Hade, Abidin Djalla, Ayu Dwi Putri Rusman

Program Studi Kesehatan Masyarakat Fakultas Ilmu Kesehatan Universitas Muhammadiyah Parepare (sadrianianhy@gmail.com)

\begin{abstract}
ABSTRAK
Sistem Informasi kesehatan adalah salah satu dari enam "building block" atau komponen utama dalam sistem kesehatan di suatu negara dan merupakan suatu pengelolaan informasi di seluruh tingkat pemerintah secara sistematis dalam rangka penyelenggaraan pelayanan kepada masyarakat. Tujuan penelitian ini adalah untuk mengetahui kualitas informasi di Rumah Sakit Andi Makasaau Parepare sebelum dan setelah adanya SIMRS.Metode penelitian ini menggunakan metode observasi/survey lapangan. Data diperoleh dengan melakukan wawancara kepada 13 responden yang di jadikan sampel mulai bulan Juli sampai Agustus 2018. Analisis penelitian yang diolah secara manual dengan mengelompokkan hasil wawancara sesuai tujuan penelitian. Selanjutnya disajikan secara kualitatif dalam satu matriks dan dalam bentuk analasis isi. Hasil penelitian menunjukkan bahwa ada perbedaan antara sebelum dan sesudah adanya SIM-RS. Rumah Sakit diharapkan mampu mempertahankan dan mengembangkan pemanfaatan teknologi informasi pelayanan kesehatan bagi masyarakat.
\end{abstract}

Kata Kunci : Kualitas informasi, SIM-RS

\begin{abstract}
The health of information system is one of the six "building block" or main component in the health system in a country and it is a systematic management of information at all levels of the government in order to provide services to the community. The aim of this study is to determine the quality of information in Andi Makkasau Parepare before and after the SIM-RS. This research method uses observation's method / field survey. Data was obtained by conducting interviews with 13 respondents who were sampled starting from July to August 2018. . Then it is presented qualitatively in one matrix and in the form of content analysis. The results of this study indicate that there are the differences between before and after SIM-RS. Hospital is expected to be able to maintain and develop the use of information technology for helth services for the community.
\end{abstract}

Keywords : Information quality, the SIM-RS 
PENDAHULUAN

Penerapan SIM-SR juga telah di amanatkan oleh Undang-undang Nomor 36 Tahun 2009 Tentang Kesehatan telah diamanatkan bahwa untuk menyelenggarakan upaya kesehatan yang efektif dan efesien diperlukan informasi kesehatan yang diselenggarakan melalui sistem informasi dan lintas sektor. Setiap penyelenggara fasilitas kesehatan, termasuk yang menyelenggarakan fasilitas pelayanan kesehatan harus menyediakan infrastruktur sistem informasi kesehatan kesehatan, meliputi kelembagaan perangkat, teknologi, dan sumber daya manusia PP pasal 45 No. 46 Tahun 2014. ${ }^{1}$

Sistem informasi kesehatan adalah salah satu dari enam "building block" atau komponen utama dalam sistem kesehatan disuatu negara. Keenam komponen (building block) sistem kesehatan tersebut, yaitu service delivery (pelaksaan pelayanan kesehatan), medical product, vaccine, and technologies (produk medis, vaksin dan teknologi kesehatan), health workdforce (tenaga medis), health system financing (sistem pembiayaan kesehatan), health in formation system (sistem informasi kesehatan), leadership and governance atau kepemimpinan dan pemerintah. $^{2}$
Sistem informasi merupakan suatu pengelolaan informasi diseluruh tingkat pemerintah secara sistematis dalam rangka penyelenggaraan pelayanan kepada masyarakat. Sistem informasi kesehatan yang efektif memberikan dukungan informasi bagi proses pengambilan keputusan semua jenjang administrasi kesehatan, khususnya di Rumah Sakit Umum Daerah Andi Makkasau Parepare yang menjadi unit pelayanan kesehatan dasar. Sistem informasi kesehatan dikembangkan dalam rangka mendukung pencapaian visi dan misi pembangunan kesehatan Indonesia, yaitu Indonesia Sehat $2025 .^{3}$

Instalasi yang ada di Rumah Sakit Umum Daerah Andi Makkasau Parepare semuanya terhubung dengan Sistem Informasi Manajemen Rumah Sakit (SIMRS). Pemasangan Sistem Informasi Manajemen (SIM) di Rumah Sakit Umum Daerah Andi Makkasau di mulai pada tahun 2015 dan sampai saat ini tidak pernah terputus karena pada saat pengimputan sistem tidak boleh terhenti hal ini dapat membuat data yang di input bermasalah, permasalahan teknis yang terjadi seperti mati lampu dapat di antisipasi dengan UPS. 
Pihak Rumah Sakit bekerja sama dengan pendor dalam proses pengembangan sistem dan teknisi dimana pihak Rumah Sakit hanya membuat perancangan program dan konsep selanjutnya. Pihak pender akan menjalankan dan menyediakan kebutuhan pihak Rumah Sakit. Rumah Sakit akan mengelola sendiri sistem informasi manajemen (SIM) sesuai apa yang di butuhkan.

\section{BAHAN DAN METODE}

Motode penelitian ini yang digunakan dalam penelitian adalah metode observasi/survey lapangan (observasional deskriptif). Dalam metode survei akan dilakukan wawancara langsung kepada pihak Rumah Sakit dan pihak-pihak yang terkait. Penelitian ini dilaksanakan di RSUD Andi Makkasau Parepare selama 2 bulan yaitu pada bulan Mei-Juni 2018. Adapun instrumen dalam penelitian ini dilakukan oleh peneliti sendiri dengan metode wawancara menggunakan alat perekam suara, kamera dan alat tulis. Jumlah pakar/praktisi sebagai sampel yang diisyaratkan cukup beberapa orang dengan prioritas yang memiliki tingkat pemahaman, penguasaan, dan/atau terlibat langsung dalam upaya penerapan SIM-RS. Populasi yang ditetapkan yaitu 13 orang yang memahami tentang SIM-RS. Penelitian ini menggunakan teknik total sampling dimana jumlah sampel sama dengan jumlah populasi, maka responden yang diteliti terdiri 13 orang dari berbagai bidang yang berbeda, yaitu pemgolahan data elektronik (PDE), rawat jalan, rawat inap, UGD, laboratorium, radiologi, penunjang pelayanan, Gizi, apotik dan Data primer diperoleh dari hasil wawancara langsung dengan responden menggunakan alat perekam suara, kamera dan alat tulis. Data sekunder diperoleh melalui bagian sistem informasi manajemen rumah sakit terkait penelitian ini. Data yang diperoleh dari hasil wawancara diolah secara manual dengan mengelompokkan hasil wawancara sesuai tujuan penelitian.

\section{HASIL}

Deskripsi karakteristik responden menguraikan atau memberikan gambaran mengenai identitas responden. Sampel dikelompokkan menjadi beberapa kelompok yaitu: karakteristik umur responden, karakteristik pekerjaan, karakteristik berapa lama menangani sistem informasi manajemen rumah sakit. Hasil penelitian menunjukkan bahwa responden dengan lama bekerja 4-6 tahun 
yang paling banyak dalam penelitian ini sebanyak 5 orang atau $38,4 \%$ lalu responden yang lama bekerja 1-3 tahun sebanyak 4 orang atau 30,8\% begitupun dengan responden yang lama bekerja 7-9 tahun sebanyak 4 orang atau $30,8 \%$. Responden dengan lama menangani sistem informasi manajemen 4-6 tahun yang paling banyak dalam penelitian ini sebanyak 7 orang atau $53,8 \%$ lalu responden yang lama menangani sistem informasi manajemen 1-3 tahun sebanyak 2 orang atau $15,4 \%$ begitupun dengan responden yang lama menangani sistem informasi manajemen 7-9 tahun sebanyak 4 orang atau 30,8\%. Selanjutnya responden dalam instalasi yang paling banyak menangani sistem informasi manajemen yaitu instalasi PDE sebanyak 4 orang atau 30,7\% sedangkan instalasi Rawat Jalan, Penunjang Pelayanan, Gizi, Rawat Inap, UGD, Laboratorium, Apotik, Radiologi dan ICU ada 1 orang atau 7,7\%

\section{PEMBAHASAN}

Menurut Peraturan Menteri

Kesehatan RI Nomor 82 tahun 2013 tentang sistem informasi manajemen rumah sakit: pasal 1 disebutkan bahwa sistem informasi manajemen rumah sakit yang selanjutnya disebut dengan SIM-RS yang merupakan suatu sistem teknologi informasi komunikasi yang memproses dan mengintegrasikan seluruh alur proses pelayanan rumah sakit dalam bentuk jaringan koordinasi, pelaporan, dan prosedur administrasi untuk memperoleh informasi secara cepat dan akurat. ${ }^{4}$

RSUD Andi Makkasau Parepare sebelum adanya sistem informasi manajemen pelayanan kesehatan masih menggunakan waktu sekitaran 1 jam untuk proses pengimputan, hal ini di karenakan proses pengimputan data yang dipakai masih manual dan banyaknya proses yang dilalui seperti pengumpulan data pasien dari berbagai prosedur yang dijalani seperti loket pendaftaran rekam medic dan diagnosis dari dokter serta informasi dari apotik semua itu harus digabung menjadi satu.

RSUD Andi Makkasau Parepare dalam proses pengimputan data yang masih memakai secara manual membutuhkan waktu sekitar 1 jam. Karena dalam suatu sistem yang menggunakan cara menulis masih membutuhkan waktu yang cukup lama untuk pengimputan data, sehingga pengimputan data yang menggunakan secara manual proses pengimputannya masih sangat lambat. Dibandingkan dengan proses pengimputan 
data yang sudah menggunakan sistem informasi manajemen rumah sakit.

Rangkaian kegiatan sistem informasi pelayanan kesehatan yang dijalankan oleh Rumah Sakit Umum Daerah Andi Makkasau Parepare, sub sistem input merupakan proses awal dari sebuah perjalanan arus informasi. Sub sistem input atau data masukan, yaitu aktivitas pemasukan data seperti registrasi pasien, yang antara lain pencatatan dan pemeriksaan data pasien masuk untuk berobat dengan tujuan untuk memperoleh keterangan atau informasi yang ada di dalamnya terdapat kegiatan menghimpun data-data dan fakta-fakta yang relevan dengan permasalahan yang ada. ${ }^{5}$

Untuk menghimpun data dan fakta, maka tidak terlepas dari adanya sumber data, untuk itu maka yang menjadi sumber data di sini adalah pasien RSUD Andi Makkasau Parepare baik pasien baru maupun pasien lama atau yang sudah pernah berobat di RSUD Andi Makkasau Parepare. Data calon pasien di dalam formulir pendaftaran mempunyai peranan dan fungsi yang penting dalam sub sitem input. Data tersebut meliputi nama, tempat tanggal lahir, jenis kelamin, status perkawinan, pekerjaan, Kartu Tanda Penduduk (KTP), nomor telepon, dan tanggal atau waktu kunjungan terakhir pasien. $^{6}$

Pendaftaran atau registrasi pasien baik pasien baru maupun lama, pasien diharuskan datang secara langsung ke unit pendaftaran RSUD Andi Makkasau Parepare. Hal ini dikarenakan unit pendaftaran RSUD Andi Makkasau Parepare belum melayani pendaftaran secara tidak langsung atau lewat telfon.

Setelah melewati proses pendaftaran atau pengumpulan data pasien, secara khusus petugas pemasukan data memasukkan data yaitu data pasien secara langsung kedalam sistem computer dengan bantuan formulir atau kartu berobat yang berisi sejumlah data untuk dimasukkan kedalam sistem computer. Dalam pegumpulan data pasien, pihak atau unit pendaftaran menggunakan formulir bagi pasien baru dan kartu berobat bagi pasien yang pernah berobat sebelumnya, dimana data formulir tersebut berisi antara lain, nama, usia, jenis kelamin, tempat tanggal lahir, alamat, dan nomor telephon yang nantinya akan membantu dalam kelengkapan data pasien.

Proses pemasukan data ataupun registrasi pasien, unit pendaftaran menggunakan terminal computer yang saling terhubung satu dengan yang lainnya 
yang di dukung dengan perangkat jaringan dengan menggunakan Local Area Network (LAN), yaitu merupakan suatu jaringan antar computer yang terbatas di suatu area yang relatif kecil, yaitu hanya di kalangan Rumah Sakit Andi Makkasau Parepare. Terminal komputer di koordinasikan oleh satu server atau komputer utama, sehingga dalam lingkup Rumah Sakit Umum Daerah Andi Makkasau Parepare ini komputernya saling terhubung.

Fungsi dari LAN sendiri sangatlah penting bagi kerja masing-masing personal atau unit dalam lingkup Rumah Sakit Umum Daerah Andi Makkasau Parepare, selain dapat menggunakan data secara bersama-sama juga menghemat biaya dan waktu. Selain itu sub sistem input sendiri merupakan hal yang penting untuk pemasukan data, sehingga dari sini bisa dilanjutkan pengolahan data selanjutnya. Dengan pengumpulan data secara elektronik melalui jaringan secara online ini akan menjadikan data yang masuk mudah di olah dan di control serta menjadi lebih aplikatif, dimana nanti data-data yang ada pada input data registrasi pasien akan diolah dan disimpan dalam data base. $^{7}$

Data pada input data registrasi pasien yang ada dalam jaringan sistem informasi pelayanan kesehatan dibuat dalam bentuk statistic yang berupa tabeltabel yang harus di isi dan berupa formulir dengan format kolom isian yang sudah ditentukan dan disesuaikan dengan keperluan kegiatan masing-masing. ${ }^{8}$

Adanya format yang telah ditentukan akan memudahkan unit pendaftaran (registrasi pasien) dalam pemasukan data-data pasien, sehingga mempercepat proses pelayanan untuk kemudian di kirim baik secara manual dan secara online kekomputer pusat (server) dalam hal ini unit rekam medis. Data-data yang disimpan dalam suatu bank data ini adalah data yang masuk ke bagian registrasi (input data) dari jaringan sistem informasi pelayanan kesehatan yang dijalankan.

RSUD Andi Makkasau Parepare sudah memfungsikan database dalam menjalankan sistem informasi pelayanan kesehatan, karena bank data di Rumah Sakit Umum Daerah Andi Makkasau Parepare secara elektronik sudah dapat menyimpan input data yang masuk ke Rumah Sakit Umum Daerah Andi Makkasau Parepare melalui sistem jaringan secara online. Jadi data yang masuk sebagai input data secara otomatis tersimpan ke dalam database. Jadi disini 
dapat dikatakan bahwa fungsi database itu adalah sebagai sumber data, yang nantinya akan digunakan sebagai bahan acuan dalam pengambilan keputusan di bidang kesehatan.

RSUD Andi Makkasau Parepare, dengan adanya sistem komputrisasi secara online dapat memudahkan dalam pengambilan data, dengan mengambil data dari database sehingga dapat menghemat waktu.

Proses pengolahan data disini, proses pemasukan data pasien kedalam sistem komputer dikerjakan oleh petugas yang berwenang, setelah data selesai maka data akan disimpan untuk dibuat laporan sebagai bentuk output. Proses pengolahan data ini meliputi pwngumpulan atau perekapan yang terjadu tiap hari untuk selanjutnya disimpan dan akan dibuat laporan baik untuk bulanan, tiga bulanan, tiap enam bulan dan laporan tahunan.

Proses assembling itu sendiri yaitu penataan berkas yang ada dalam rekam medis yang dikerjakan oleh petugas rekam medis dengan menggunakan program Excel pada sebuah unit computer yang selanjutnya akan dijadikan laporan rutin kepada unit-unit yang membutuhkan.

Pengolahan data transaksi ini perangkat lunaknya sama dengan pada proses input, yaitu menggunakan hard disk atau CPU. Sedangkan perangkat kerasnya juga sama yaitu dengan menggunakan perangkat computer, mouse, keyboard. Untuk aktivitas pengolahan data ini di Rumah Sakit Umum Daerah Andi Makkasau Parepare, khususnya untuk unit medical record memiliki 2 terminal computer dengan fungsi yang berbeda, yaitu satu unit untuk computer khusus pembuatan laporan, dan satu unit computer untuk pemrosesan data atau dokumen mengenai riwayat penyakit pasien secara keseluruhan.

Unit layanan kesehatan di RSUD Andi Makkasau Parepare mempunyai 7 unit komputer yang antara lain 2 unit computer di unit pendaftaran, 2 unit computer di unit rekam medis, 2 unit computer di unit kasir, dan 1 unit di UGD. Proses penyimpanan data, data adminstratif yang ada di unit rekam medis adalah berupa arsip atau dokumen yang juga berupa file yang disimpan di computer, dimana data tersebut memuat riwayat penyakit pasien. Kemudian dalam penyimpanan data, setiap pencatatan data pasien yang dibuat akan disimpan dalam database masing-masing computer sesuai fungsinya, yaitu fungsi penyimpanan data 
atau dokumen dan fungsi data yang dikemudian akan dibuat laporan.

Memasukkan setiap data ini kedalam computer, atau tiap pemrosesan, tiap petugas yang bertugas dibagian unit tersebut mempunyai password untuk log in atau masuk ke server atau jaringan, sehingga dapat diketahui nama petugas ketika pencatatan atau record input data dalam proses input data. Hal ini dimaksudkan, bahwa petugas yang mengisikan ini bertanggung jawab jika ada kesalahan dalam penulisan atau pengisian dalam proses pengolahan data.

Dengan demikian untuk media penyimpanan data yang dilakukan selain di simpan dalam terminal computer yang telah dilengkapi CPU juga secara otomatis di backup di computer servernya atau computer utama yaitu dalam hard disk yang mempunyai kapasitas penyimpanan sampai ratusan Giga Bytes (GB), sehingga untuk backup data tidak perlu menggunakan penyimpanan sekunder seperti flash disk ataupun CD (Compact Disk).

Cara penyimpanan dokumen di tiap unit Rumah Sakit Umum Daerah Andi Makkasau Parepare ada dua cara yaitu baik secara manual dan secara elektronik yang sudah bisa di akses pada jam kerja.
Sering dirasakan bahwa rumah sakit yang masih menggunakan pola manual membutuhkan waktu yang lama dalam proses pelayanannya. Selain itu banyak pula rumah sakit yang mengalami kehilangan banyak kesempatan dalam memperoleh laba akibat dari lemahnya koordinasi antar departemen maupun kurangnya dukungan informasi yang cepat, tepat, akurat, dan terintegrasi. Rumah sakit tersebut telah kalah saing dengan rumah sakit yang telah menerapkan sistem informasi modern dalam rumah sakitnya.

Oleh karena itu, diperlukan adanya suatu sistem informasi manajemen rumah sakit yang merupakan sistem komputerisasi yang memproses dan mengintegrasikan seluruh alur proses bisnis layanan kesehatan dalam bentuk jaringan koordinasi, pelaporan, dan prosedur administrasi untuk memperoleh informasi informasi secara cepat, tepat, dan akurat. Tidak hanya itu, rumah sakit juga memerlukan SIM-RS yang terintegrasi demi mendukung adanya peningkatan pelayanan rumah sakit terhadap pasien.

Rumah sakit sebagai institusi pelayanan kesehatan yang menyelenggarakan pelayanan kesehatan 
perorangan secara paripurna yang menyediakan pelayanan rawat inap, rawat jalan, dan gawat darurat. Rumah sakit membutuhkan keberadaan sistem informasi manajemen yang akurat untuk meningkatkan pelayanan kepada para pasien serta lingkungan terkait lainnya. Saat ini rumah sakit dituntut untuk meningkatkan kinerja dan daya saing sebagai badan usaha yang tidak mengurangi misi sosial yang di embannya. Rumah sakit juga harus merurmuskan kebijakan strategis pada internal organisasi, manajemen, dan sumber daya manusianya serta mampu secara cepat dan tepat mengambil keputusan untuk peningkatan kualitas pelayanan kesehatan terhadap masyarakat lain. ${ }^{8}$

Sistem informasi rumah sakit ini mengacu pada sistem komputer yang di rancang untuk mengelola semua informasi medis dan administratif dirumah sakit agar tenaga kesehatan dapat melakukan pekerjaan mereka dengan lebih efektif dan efesiensi. Selain itu, HIS mengelola semua aktivitas pemrosesan informasi di dalam rumah sakit untuk mendapatkan layanan perawatan pasien berkualitas tinggi dan penelitian medis. $^{9}$

Pengguna informasi rumah sakit mengharapkan departemen sistem informs manajemen di rumah sakit dapat membantu menyelesaikan berbagai tugas lain, seperti pemilihan perangkat keras dan perangkat lunak, pemasangan, pemecahan masalah, integrasi dengan jaringan lain, modifikasi sistem atau pengembangan, pendidikan, konversi data menjadi informasi yang bermakna untuk pengambilan keputusan, dan lain-lain. Pengguna sistem informasi manajemen di rumah sakit dapat diidentifikasi menjadi internal dan eksternal. Pengguna internal adalah dokter, perawat, teknisi laboratorium, Apoteker, dan lainnya di dalam fasilitas kesehatan yang berinteraksi dengan proses esensial. Pengguna eksternal adalah pasien, keluarga pasien, penyedia asuransi, peneliti layanan kesehatan.

Aplikasi sistem informasi telah berkontribusi pada pengelolaan layanan kesehatan yang lebih baik dan pemberian perawatan dengan menciptakan lingkungan yang kondusif bagi peningkatan akses dan kualitas layanan pada pasien dan dengan mendukung basis pengetahuan yang dibutuhkan untuk pengambilan keputusan klinis dan administratif.

Berkembangnya teknologi sistem informasi, maka penyajian informasi yang 
cepat dan efesiensi sangat dibutuhkan oleh setiap orang. Perkembangan teknologi yang semakin pesat saat ini menuntut diubahnya pencatatan manual menjadi sistem yang terkomputerisasi. Demikian juga halnya pembayaran pasien pada suatu rumah sakit. Rumah sakit sebagai salah satu institusi pelayanan umum di bidang kesehatan membutuhkan keberadaan suatu sistem informasi yang akurat, handal, serta cukup memadai untuk meningkatkan pelayanannya kepada para pasien serta lingkungan terkait lainnya. Sistem informasi rumah sakit digunakan untuk mempermudah dalam pengelolaan data pada rumah sakit. Sistem ini seharusnya sudah menggunakan metode komputerisasi. Karena dengan penggunaan metode komputerisasi, proses pengimputan data, proses pengambilan data, maupun proses pengapdetan data menjadi sangat mudah, cepat dan akurat. ${ }^{10}$

Sedangkan setelah adanya sistem informasi manajemen Rumah Sakit Umum Daerah Andi Makkasau Parepare, data yang dulunya diproses selama 1 jam sekarang sudah bisa diproses dalam waktu 15 menit dan disimpan di bank data yang merupakan kumpulan data yang strategis dari unit pendaftaran yang kemudian disimpan di computer pusat atau server dan dapat di akses melalui media elektronik.

Sistem Informasi Manajemen

Rumah Sakit (SIM-RS) merupakan himpunan atau kegiatan dan prosedur yang terorganisasikan dan saling berkaitan serta saling ketergantungan dan dirancang sesuai dengan rencana dalam usaha menyajikan informasi yang akurat, tepat waktu dan sesuai kebutuhan guna menunjang proses fungsi-fungsi manajemen dan pengambilan keputusan dalam memberikan pelayanan kesehatan di rumah sakit.

Sistem Informasi Manajemen Rumah Sakit (SIM-RS) ini ditujukan untuk menunjang fungsi perencanaan dan evaluasi dari penampilan kerja rumah sakit, antara lain adalah jaminan mutu pelayanan rumah sakit yang bersangkutan, pengendalian keuangan dan perbaikan hasil kerja rumah sakit tersebut, kajian dalam penggunaan dan penaksiran permintaan pelayanan kesehatan rumah sakit oleh masyarakat, perencanaan dan evaluasi program rumah sakit, penyempurnaan laporan rumah sakit serta untuk kepentingan pendidikan dan penelitian.

SIM-RS merupakan himpunan atau kegiatan dan prosedur yang 
terorganisasikan dan saling berkaitan serta saling ketergantungan dan dirancang sesuai dengan rencana dalam usaha menyajikan infirmasi yang akurat, tepat waktu dan sesuai kebutuhan guna menunjang proses fungsi-fungsi manajemen dan pengambilan keputusan dalam memberikan pelayanan kesehatan di rumah sakit.

Dapat dikatakan bahwa SIM-RS ini adalah alat yang digunakan untuk memudahkan proses manajemen rumah sakit. Dengan SIM-RS manajemen bisa menentukan tindakan yang pas sesuai dengan informasi yang terkumpul dalam sistem. Misalnya jumlah pasien untuk suatu penyakit dengan ketersediaan obat yang ada. Jika informasi yang dimiliki pihak manjemen tidak sesuai dengan faktanya tentu bisa terjadi hal fatal. Karena itu sangat penting sekali SIM-RS ini diterapkan di rumah sakit.

Mekanisme SIM-RS ini merupakan sistem tentu saja terdapat beberapa prosedur dalam penerapannya. Seperti prosedur pemrosesan data yang diambil melalui teknologi informasi yang sudah terintegrasi. Sebelum menerapkan prosedur tersebut ada beberapa hal yang perlu dipersiapkan oleh pihak rumah sakit. Hal-hal berikut ini memegang peran penting dalam kesuksesan SIM-RS diantaranya, Software (program sistem informasi manajemen), Hardware (komputer, printer, dan perangkat keras lainnya), Networking (jaringan LAN, wireless dan lainnya), SOP (standar operasional prosedur), Komitment (komitment semua unit/instalasi yang terkait untuk sama-sama menjalankan sistem karena sistem tidak akan berjalan tanpa di input), SDM (sumber daya manusia seperti tenaga teknis atau tenaga ahli yang berkualitas.

Untuk hal pertama yaitu software ada beberapa faktor yang perlu diperhatikan dalam memilih teknologi yang sesuai diantaranya, Price, Performance, Flexibility, Survivability. Semua faktor ini akan menentukan bagaimana kualitas dari software sistem informasi yang akan diterapkan di dalam rumah sakit. Semakin baik kualitas software tentu saja proses manajemen akan semakin terbantu.

\section{KESIMPULAN DAN SARAN}

Berdasarkan hasil penelitian dan pembahasan sebelumnya maka dapat disimpulkan bahwa RSUD Andi Makkasau Parepare Sebelum adanya Sistem Informasi Manajemen, waktu yang 
dibutuhkan sekitar 1 jam karna proses pengimputan data yang dipakai masih manual, RSUD Andi Makkasau Parepare setelah adanya Sistem Informasi Manajemen, data yang dulunya diproses selama 1 jam sekarang sudah bisa diproses dalam waktu 15 menit dan disimpan di bank data. Jadi, Sistem Informasi Manajemen di Rumah Sakit Umum Daerah Andi Makkasau Parepare sudah berjalan dengan baik hal ini dapat dilihat

\section{DAFTAR PUSTAKA}

1. A. Anwar, \& Suyitno. Analisis Penerapan Sistem Informasi Manajemen Dan Kompetensi Pegawai serta Pengaruhnya terhadap Kinerja Pegawai. Sekolah Tinggi Ilmu Ekonomi; 2017.

2. Damayanti \& Santi. Gambaran Penerapan Sistem Informasi Manajemen Kesehatan Berbasis WEB di Puskesmas. Makassar: Alauddin Makassar; 2015.

3. Muhammad, R., \& Zilfadhillah, A. Gambaran Penerapan Sistem Informasi Manajemen Kesehatan Berbasis WEB di Puskesmas. Makassar: Alauddin Makassar; 2015.

4. Kemenkes, Damayanti, \& Santi. Gambaran Penerapan Sistem Informasi Manajemen Kesehatan Berbasis WEB dari kelancaran pelayanan pada pasien. Untuk itu diharapkan kepada Rumah Sakit Umum Daerah Andi Makkasau Parepare mampu mempertahankan atau mengembangkan pemanfaatan teknologi informasi dan sistem informasi pelayanan kesehatan bagi masyakat, dan memberikan pelatihan kepada semua staf agar dapat menjalankan Sistem Informasi Manajemen Rumah Sakit.

Di Puskesmas Makassar: Alauddin Makassar; 2015.

5. S, T., \& Lestari, E. A. Analisis Penerapan Sistem Informasi Manajemen Dalam Upaya Peningkatan Pelayanan Kesehatan . Parepare: Rumah Sakit Andi Makkasau; 2013.

6. Kusharjanti F. Sistem Informasi

Manajemen Rumah Sakit (SIM RS);

2015. [Serial Online] [Diakses pada tanggal 24 Maret 2018]. Available at: http://Fiastri k.blogspot.com

7. Achmad, \& Lestari, E. A. Analisis Penerapan Sistem Informasi Manajemen Dalam Upaya Peningkatan Pelayanan Kesehatan. Parepare: Rumah Sakit Umum Daerah Andi Makkasau; 2013.

8. Azwar, A., \& Fany, I. W. Kualitas Pelayanan Rawat Inap di Rumah Sakit 
Umum. Makassar: Universitas Hasanuddin; 2016.

9. Rafless. Sistem Informasi Manajemen Rumah Sakit; 2015. [Serial Online] [Diakses pada tanggal 09 Juli 2018]. Available at: pada http://bahankuliahkesehatan.Blogspot. com.

10. Rijal, F., Dangnga, M. S., Usman, U., \& Novitasari, N. (2019). Pengaruh Etika dan Kinerja Tenaga Kesehatan terhadap Pemberian Pelayanan Kesehatan Pasien di Puskesmas Madising $\mathrm{Na}$ Mario Kota
Parepare. Jurnal Ilmiah MANUSIA DAN KESEHATAN, 2(1), 12-25.

11. Usman, Usman. "Analisis Kinerja Tenaga Kesehatan pada Puskesmaslapadde Kota Parepare." Media Kesehatan Masyarakat Indonesia 12.1 (2016): 2128.

12. Zaenal. Sistem Informasi Manajemen Rumah Sakit; 2015. [Serial Online] [Diakses pada tanggal 15 April 2018]. Available at: pada http://Duniaberbagi.wordpress.com. 